\title{
ENVIRONMENTAL SUSTAINABILITY EDUCATION AT THE UNIVERSITY OF MICHIGAN: COLLABORATION WITH INDUSTRY TO PROVIDE EXPERIENTIAL LEARNING OPPORTUNITIES
}

\author{
Angela D. Lueking, Deborah A. Ross, Walter J. Weber, Jr. \\ Department of Chemical Engineering \\ University of Michigan \\ Ann Arbor, MI, 48109-2125
}

\begin{abstract}
The Concentrations in Environmental Sustainability (ConsEnSus) Program at the University of Michigan is a new multi-disciplinary opportunity for graduate students in the College of Engineering to pursue interests in environmental sustainability while obtaining a traditional engineering Master's degree. Students from several engineering departments complement traditional disciplinary course requirements with courses in environmental regulations, policies, and technology. A required case studies course of the ConsEnSus Program brings practicing engineers together with students to discuss real-world sustainability problems. The industrial participants interactively present relevant case studies, and provide opportunities for experiential learning through classroom activities and term projects. This paper will further explain the ConsEnSus Program, its implementation, the initial successes of the program, and the case studies course and term project that was developed in collaboration with industry.
\end{abstract}

\section{Motivation}

The Concentrations in Environmental Sustainability (ConsEnSus) Program is designed for all engineers rather than just the environmental specialist. The motivation for ConsEnSus derives from the increasing need for engineers to not only interact effectively with environmental specialists, but to be educated first-hand in matters of environmental regulations, policies, practices, and the implementation of clean technologies. The ConsEnSus Program addresses this need by training and mentoring engineering students in the development and implementation of forward looking practices and products that anticipate and circumvent environmental problems.

\section{Concentration Requirements}

The basic requirement for ConsEnSus is successful completion of twelve credit hours of course work designed to educate a student in critical elements of environmental sustainability in the context of his/her professional practice. With completion of these credits, students receive a 
designation on his/her transcript and diploma. A key feature of the ConsEnSus Program is that it requires no additional coursework beyond the traditional degree requirements. The required twelve credit hours for ConsEnSus also fulfill requirements of the traditional Master's degree. Thus, the program is a template that can be applied to virtually any degree program. The ConsEnSus Program design was accomplished by identifying pre-existing courses with an environmental component.

The approved courses — whether generic or department specific — are subdivided into three categories with respect to intellectual content: A. Environmental Law and Regulations; B. Environmental Assessment and Policy; and C. Environmental Science and Technology. Students must select courses from at least two of these three categories in completion of the twelve credit hours. The overall goal of the approved courses is to enhance the student's environmental literacy and competency in addressing environmental issues in the context of his/her professional practice.

ConsEnSus requires two common courses for all participants, including the course Industrial Ecology and the course Case Studies in Environmental Sustainability. The case studies class was recently added to the curriculum specifically for the ConsEnSus Program, and has led to industrial collaborations, which provide students experiential learning opportunities in terms of in class activities and student term projects. The details of the class and the project collaborations are described in detail in the following sections.

\section{Capstone Case Studies Course}

The class, "Case Studies in Environmental Sustainability", is required of all ConsEnSus participants, and is also open to the general student population. The primary objective of this class is to expose students to a wide range of environmental sustainability case studies. In this way, the course helps to produce knowledgeable engineers capable of meeting both industrial and environmental challenges. The class provides students with weekly real world examples taken from industry and presented by industrial representatives that incorporate concepts including green technologies, design for the environment, and waste minimization. In order to equip each student for the class, introductory sessions focus on defining sustainability and discussing corporate perspectives. An introductory panel session is used to give students background information on corporate finance and policy issues not normally encountered in a traditional engineering class.

The secondary objective of the class is to allow students to creatively approach problems and hone their quantitative problem solving skills. Incorporation of mixed methods (including case studies) has been linked to increased student productivity and is suspected to retain a more diverse student body, in terms of how students approach and solve problems. Using directed assignments that require the students to form such links fosters their creativity and critical thinking skills. ${ }^{1}$ To encourage students to "think outside the box", the class sessions and presentations are designed to be as interactive as possible; this classroom format is based on Wankat's three-word summary of research on student learning: "involved students learn". 2 
Students are asked to participate in discussions, and homework requires students to present preliminary solutions to sustainability problems provided by the industrial participants.

Interdisciplinary student groups simulate real-world engineering teams and require students to evaluate case studies before, during, and after each class.

The content of the course was designed with engineering students in mind. Higher-level thinking skills, such as analysis, synthesis, and evaluation are required of engineers. Presentations incorporate general engineering fundamentals such as process flow diagrams, process control, mass balances, etc. All presentations incorporate the unifying theme of the triple bottom line; thus economic, environmental, and societal considerations are used in each presentation. Most guest speakers are practicing engineers who have faced challenges in sustainability in the course of their day-to-day activities. This also provides several networking opportunities for both the students and the industrial participants.

Development of critical thinking can be done by describing the thought process used in problem solving during lectures, involving students in the problem solving during class, and care ful selection of homework assignments. ${ }^{3}$ To provide a uniform format for the students and enhance critical thinking, guest speakers are encouraged to design interactive discussions by:

(1) providing appropriate introductory and background materials for the problem prior to the presentation;

(2) presenting the problems to be addressed from the perspective of a manager approaching a team of engineers with a new project;

(3) allotting sufficient time in the presentation for students to brainstorm and/or discuss their initial analysis from the introductory material;

(4) acknowledging student comments and ideas, while discussing the advantages and constraints of each suggestion; and,

(5) describing the real-world solution that was implemented, an explanation of why it was chosen, and any follow-up issues that may have been generated.

\section{Student Term Project}

Students who elect the case studies course for three credits must complete a group term project. This winter semester (January 2003), the student term project consists of a collaborative effort designed with Visteon Corporation. The students are asked to evaluate and recommend opportunities for the elimination of HCFC solvents (an ozone-depleting compound) used in precision cleaning of Climate Systems test stands at Visteon. Each group will evaluate potential solutions to this problem based on (1) effectiveness of cleaning, (2) health \& safety considerations, (3) economic feasibility, (4) technological options and (5) business considerations. At the end of the semester each group will be required to submit a written report similar to what is required of an engineer at Visteon. The advantage of this term project format is that students will be able to participate first hand in a problem of industrial importance; in fact, the term project resembles a small internship and/or co-operative educational experience. This type of experiential learning will allow the students to get hands on experience in the discipline and to see the direct application of sustainability concepts. 
In parallel, a summative assessment will be used to determine the value added from the industry sponsored student term project. For example, the differential learning provided by the term project in terms of both student comprehension of sustainability concepts and the implementation of sustainability projects in a corporate setting will be studied.

\section{Program Implementation}

There are currently five departments participating in the ConsEnSus Program, including: Atmospheric, Oceanic, and Space Sciences (AOSS), Chemical Engineering (ChE), Civil and Environmental Engineering (CEE), Naval Architecture and Marine Engineering (NAME), and Mechanical Engineering (ME). Several key steps were required to implement the ConsEnSus Program within these departments. The ConsEnSus Program was an initiative of the College's Institute for Environmental Sciences, Engineering and Technology (IESET). IESET provided a support base for the ConsEnSus Program and helped to establish cross-disciplinary faculty interest. The initial structuring required joint cooperation between the specific departments and the ConsEnSus Program Office. Working with departments to identify existing classes that were environmentally relevant was essential to the structuring of a flexible program. Each department desiring to participate in ConsEnSus was required to submit their individual degree plans and requirements through regular departmental and College-wide channels. The motivation for the departments to participate in the program include the popularity of the program, the enhanced competitiveness of graduates, and potential affiliations with industrial partners.

Currently, the program is administered by the home department, with guidance as desired and requested by that department from the ConsEnSus Program Office, which serves to co-audit the ConsEnSus component of the degree. A department admits students into a master's level graduate program according to the customary procedures of that department. At an individual department's discretion, the ConsEnSus Program can be used to aid in student recruitment (this has been a successful enterprise for several participating departments). Once admitted to the department, a student is advised by a departmental representative of the opportunity to participate in the concentration. Final overall degree approval authority is vested in the department.

The recruiting of industrial participants was a key factor in the planning and successful implementation of the case studies course. A database of potential participants was developed based on location, industry sector, and case study content. When recruiting the industrial participants, they were given clear guidelines as to the content and structure of the course, as well as deadlines for submission of background information. Continuing communication was a key component of well-received presentations. Industrial feedback collected after the presentations indicated that key driving forces for participation was: communication of positive corporate activities, living the corporate values, and the opportunity for networking and collaboration.

\section{LITERATURE CITED}

Proceedings of the 2003 American Society for Engineering Education Annual Conference \& Exposition Copyright? 2003, American Society for Engineering Education 
1. R.M. Felder, Engineering Education, 1987, 77, 222

2. P.C. Wankat, The Effective, Efficient Professor, Allyn and Bacon, 2002, p. 42

3. H.S. Fogler, Teaching Critical Thinking, Creative Thinking, and Problem Solving in the Digital Age, Phillips Petroleum Lecture, Oklahoma State University, April 25, 1997

\section{bIOGRAPHICAL INFORMATION}

ANGELA LUEKING is a $\mathrm{PhD}$ candidate in Chemical Engineering and expects to complete her $\mathrm{PhD}$ studies in August 2003. Prior to her PhD studies, she served as an environmental manager in industry and brings this perspective to the ConsEnSus Program. She was the graduate instructor for "Case Studies in Environmental Sustainability" in its first year and currently serves as a graduate advisor for the ConsEnSus Program.

DEBORAH ROSS is a PhD student in Chemical Engineering and plans to receive the ConsEnSus Program designation. She currently serves as the graduate student instructor for "Case Studies in Environmental Sustainability" and is coordinating the implementation of the industry-focused student term project. She is also a graduate advisor for the ConsEnSus Program.

WALTER J. WEBER, JR. is the Gordon Maskew Fair and Earnest Boyce Distinguished University Professor and serves as the director of the ConsEnSus Program. He is the author of three books and approximately 300 publications describing his research on advanced technologies for water treatment and reclamation, hazardous substance management and control, and the fate and transport of contaminants in surface and groundwater systems. 